\title{
Parâmetros fisiológicos em videiras 'Paulsen 1103’ (Vitis berlandieri x Vitis rupestris) inoculadas com fungos micorrízicos arbusculares em solo contaminado com cobre
}

\author{
Physiological parameters in vines 'Paulsen 1103' (Vitis berlandieri x Vitis rupestris) inoculated with \\ mycorrhizal fungi in soil contaminated with copper
}

\author{
Daniel José Rosa ${ }^{1}$, Vítor Gabriel Ambrosini ${ }^{2}$, Gustavo Brunetto ${ }^{3}$, Cláudio Roberto Fonsêca Sousa Soares ${ }^{1}$, \\ Marcelo Borghezan ${ }^{1}$, Rosete Pescador ${ }^{1}$ \\ ${ }^{1}$ Programa de Pós-Graduação em Recursos Genéticos Vegetais, Departamento de Fitotecnia, Universidade Federal de Santa Catarina, \\ Florianópolis, Santa Catarina, Brasil. \\ ${ }^{2}$ Programa de Pós-Graduação em Agroecossistemas, Departamento de Engenharia Rural, Universidade Federal de Santa Catarina, Florianópolis, \\ Santa Catarina, Brasil. \\ ${ }^{3}$ Departamento de Solos e Programa de Pós-Graduação em Ciência do Solo, Universidade Federal de Santa Maria, Santa Maria, Rio Grande do \\ Sul, Brasil.
}

*corresponding author: Tel: +55 483721 5333, e-mail: danielrosa.agro@gmail.com

(Manuscrito recebido em 28.07.2015. Aceite para publicação em 20.03.2016)

\section{RESUMO}

A aplicação de fungicidas foliares em vinhedos incrementa o teor de cobre $(\mathrm{Cu})$ no solo, que pode modificar parâmetros fisiológicos de videiras jovens transplantadas em solos de vinhedos erradicados. A inoculação com fungos micorrízicos arbusculares (FMA) pode reduzir a disponibilidade de $\mathrm{Cu}$ às videiras e, com isso, reduzir o efeito tóxico do $\mathrm{Cu}$ nas células de plantas jovens. O trabalho objetivou avaliar alterações fisiológicas no porta-enxerto de videira 'P1103' (Vitis berlandieri x Vitis rupestris) cultivado em solo com alto teor de Cu e inoculado com espécies de FMA. O experimento foi conduzido em casa de vegetação. As videiras foram acondicionadas em vasos. No momento do transplante, as raízes foram inoculadas com os FMA: Dentiscutata heterogama, Acaulospora morrowiae e Rhizophagus clarus, além de um tratamento controle, não-inoculado. O experimento foi conduzido em blocos ao acaso com sete repetições. O cultivo foi realizado durante 76 dias, ao final do qual foi avaliado a altura de planta, a área foliar, as taxas de trocas gasosas, colonização micorrízica, matéria seca de raízes, caule e folha; número de folhas, diâmetro de colmo, teores de carboidratos solúveis totais, amido total, clorofila a, b e total, carotenoides, teores de Cu e P nas plantas. Dentre os FMA avaliados, o $R$. clarus promoveu maior benefício para o crescimento das plantas e reduziu o teor de Cu nos tecidos. As maiores taxas de assimilação de $\mathrm{CO}_{2}$ e condutância estomática ocorreram nas plantas inoculadas com D. heterogama. Os FMAs estudados amenizaram a toxicidade do cobre às videiras jovens.

\section{SUMMARY}

The application of foliar fungicide in vineyards increases the copper content $(\mathrm{Cu})$ in the soil, which can modify physiological parameters of young vines transplanted in soil vineyards eradicated. The inoculation with mycorrhizal fungi (AMF) can reduce the availability of Cu to vines and thereby reduce the toxic effect of $\mathrm{Cu}$ in the cells of young plants. The study aimed to evaluate physiological changes in rootstock grapevine 'P1103' (Vitis berlandieri x Vitis rupestris) grown in soil with high Cu content inoculated with AMF species. The experiment was conducted in a greenhouse. The vines were placed in pots. At the time of transplantation, the roots were inoculated with the AMF: Dentiscutata heterogama, Acaulospora morrowiae and Rhizophagus clarus, plus a control treatment, non-inoculated. The experiment was conducted in randomized blocks with seven replicates. The cultivation was carried out for 76 days, and at the end it was evaluated plant height, leaf area, gas exchange rates, mycorrhizal colonization, dry matter of roots, stem and leaf; number of leaves, stem diameter, total soluble carbohydrate content, total starch, chlorophyll a, b and total, carotenoids, $\mathrm{Cu}$ and $\mathrm{P}$ content in plants. Among the evaluated FMA, $R$. clarus promoted greater benefit to the plant growth and reduced the $\mathrm{Cu}$ content in the tissues. The highest $\mathrm{CO}_{2}$ assimilation rates and stomatal conductance occurred in plants inoculated with D. heterogama. AMF studied eased the toxicity of copper to young vines.

Palavras-chave: metal pesado, micorrizas arbusculares, assimilação de $\mathrm{CO}_{2}$, Vitis sp.. Key words: heavy metal, arbuscular mycorrhizae, $\mathrm{CO}_{2}$ assimilation, Vitis sp..

This is an Open Access article distributed under the terms of the Creative Commons Attribution License (http://creativecommons.org/licenses/by/4.0), which permits unrestricted use, distribution, and reproduction in any medium, provided the original work is properly cited. 


\section{INTRODUÇÃO}

A umidade elevada nas regiões vitivinícolas do Sul do Brasil torna as videiras suscetíveis a patógenos causadores de doenças fúngicas foliares, como o míldio (Plasmopara viticola), que podem causar grandes perdas de produção (Sônego et al., 2005). Com o intuito de controlar essas doenças, as videiras são submetidas a aplicações sucessivas de fungicidas cúpricos que podem adicionar até $30 \mathrm{~kg}$ de cobre $(\mathrm{Cu})$ $\mathrm{ha}^{-1} \mathrm{ano}^{-1}$ ao sistema de produção de uvas (Nachtigall et al., 2007; Girotto et al., 2013).

$\mathrm{O} \mathrm{Cu}$ é um nutriente essencial para o desenvolvimento da videira, pois está associado a algumas das enzimas envolvidas nas reações de oxido-reduções como o citocromo oxidase na cadeia de transporte de elétrons mitocondrial e na plastocianina que participa do transporte de elétrons fotossintéticos, além de fazer parte dos cloroplastos das folhas (Yruela, 2009; Marschner, 2012).

Quando em excesso no solo, o $\mathrm{Cu}$ pode causar modificações na morfologia e anatomia de raízes, que resultará em redução na absorção de nutrientes causando deficiência nutricional nas plantas e que pode ser diagnosticado pela análise de tecidos foliares (Kopittke et al., 2009; Toselli et al., 2009). Poderão ser afetados os parâmetros relacionados com o crescimento, dentre eles, altura das plantas, área foliar, acúmulo de biomassa e o número de folhas emitidas (Cambrollé et al., 2015).

É importante evitar o transporte de $\mathrm{Cu}$ em excesso às folhas, pois em nível celular, pode inativar ou danificar as estruturas proteicas como resultado de ligações com grupos sulfidrilas de proteínas e, assim, inibir a atividade de enzimas, ou induzir deficiência de outros íons essenciais, o que causa deficiência nos processos de transporte da célula e dano oxidativo (Yruela, 2009). Além disso, pode ocorrer alteração no transporte de elétrons da fotossíntese e na distribuição dos carboidratos no interior da planta, podendo causar acúmulo de amido nas folhas das plantas mais prejudicadas em função do baixo crescimento (Alaoui-Sossé et al., 2004; Kabata-Pendias, 2011).

Os fungos micorrízicos arbusculares (FMA) podem desempenhar função importante na proteção da toxicidade de metais pesados às plantas (Soares e Siqueira, 2008). Como estratégia de sobrevivência, os FMA possuem mecanismos para evitar a toxicidade por metais, como a produção de glomalina, uma glicoproteína que é secretada e liberada no solo proporcionando a complexação dos metais (FolliPereira et al., 2012). Além disso, os FMA podem compartimentalizar o $\mathrm{Cu}$ nos esporos sem que existam danos no seu metabolismo e, por consequência, também promove a redução da disponibilidade de Cu às raízes (Cornejo et al., 2013).

Os FMA também podem amenizar os efeitos da toxicidade de metais por meio de outros mecanismos, como a retenção dos metais no micélio fúngico ou pela melhoria do estado nutricional de fósforo $(\mathrm{P})$ das plantas simbiônticas (Soares e Siqueira, 2008; Ambrosini et al., 2015). A melhoria da nutrição de $\mathrm{P}$ às plantas pode proporcionar a formação de compostos de ligação metal-fosfato, complexando os metais nas raízes e evitando o seu transporte para a parte aérea (Soares e Siqueira, 2008). O efeito protetor dos FMA é dependente da espécie fúngica e da sua compatibilidade com a espécie vegetal (Meier et al., 2012) e também da concentração e formas químicas dos contaminantes no solo.

Desta forma, o presente trabalho objetivou avaliar alterações fisiológicas no porta-enxerto de videira 'P1103' (Vitis berlandieri x Vitis rupestris) cultivado em solo com alto teor de $\mathrm{Cu}$ e inoculado com espécies de FMA.

\section{MATERIAIS E MÉTODOS}

\section{Coleta e preparação do solo}

O solo foi coletado na camada de $0-20 \mathrm{~cm}$ de um Argissolo Vermelho (Embrapa, 2013), em um vinhedo com 40 anos de cultivo, com histórico de aplicações foliares de fungicidas cúpricos ao longo dos anos, em Santana do Livramento, região da Campanha Gaúcha (RS), região Sul do Brasil, com as seguintes coordenadas geográficas: $30^{\circ} 47^{\prime} 23.5^{\prime \prime}$ S; $55^{\circ}$ 22' 7.0', W. O solo possuía as seguintes características: areia, silte e argila 901; 53,4; 45,6 g $\mathrm{kg}^{-1}$, respetivamente; C orgânico total 7,9 $\mathrm{g} \mathrm{kg}^{-1}$ (Embrapa, 1997); pH em água 6,5; P disponível 34,8 mg kg-1 e K trocável 88,7 mg kg-1 (extrator Mehlich1); $\mathrm{Al}, \mathrm{Ca}$ e Mg trocáveis (extraídos por $\mathrm{KCl} 1 \mathrm{~mol} \mathrm{~L}{ }^{-}$ ${ }^{1}$ ), 0,$0 ; 4,4 ; 1,5$ cmolc $\mathrm{kg}^{-1}$ respetivamente e teor de $\mathrm{Cu}$ extraído por EDTA 32,9 mg kg-1, valor esse interpretado como alto pela CQFS-RS/SC (2004) (maior que $0,4 \mathrm{mg} \mathrm{kg}^{-1}$ ).

Após a coleta, o solo foi seco ao ar, passado em peneira com malha de $2 \mathrm{~mm}$, homogeneizado e, por duas vezes, esterilizado em autoclave a $121{ }^{\circ} \mathrm{C}$, em bandejas contendo $10 \mathrm{~kg}$ de solo, durante duas horas para eliminar propágulos de FMA autóctones.

\section{Obtenção do material vegetal e condução experimental}

Para o experimento, foram utilizados porta-enxertos de videira, cultivar 'P1103' (Vitis berlandieri $x$ Vitis rupestris), obtidos através da propagação in vitro, 
utilizando-se o meio de cultura DSD1 com $20 \mathrm{~g} \mathrm{~L}^{-1}$ de sacarose e 6,0 $\mathrm{g} \mathrm{L}^{-1}$ de ágar (Silva e Doazan, 1995) e, posteriormente, aclimatizados em substrato (fibra de coco e vermiculita) estéril em casa de vegetação por, aproximadamente, 60 dias. Durante a condução experimental, a temperatura ambiente mínima variou de 17,4 a $21,8^{\circ} \mathrm{C}$ e a temperatura máxima, de 30,3 a $37,7^{\circ} \mathrm{C}$.

Em seguida as plantas foram transplantadas para vasos com capacidade de $2 \mathrm{~L}$ contendo solo contaminado com $\mathrm{Cu}$ e realizada a inoculação dos FMA. O experimento foi implantado em casa de vegetação em delineamento em blocos casualizados com sete repetições e quatro tratamentos, sendo um tratamento controle não-inoculado e três espécies de FMA: D. heterogama, A. morrowiae e R. clarus. A inoculação das plantas foi realizada pela aplicação de suspensão de 100 esporos de FMA por planta. Para isso, realizou-se a extração de esporos de FMA de vasos de cultivo com Brachiaria decumbens por meio do peneiramento úmido e decantação em solução de sacarose conforme descrito em Gerdemann e Nicolson (1963).

\section{Coleta do material vegetal}

Após 76 dias de condução experimental, foi determinada a altura das plantas usando régua graduada; o diâmetro do colmo usando um paquímetro e realizada a contagem do número de folhas e de nós. Posteriormente, as videiras foram separadas em raízes, caules e folhas. Na sequência, a massa fresca (MF) de cada parte foi determinada em balança de precisão.

Uma porção da MF de cada órgão foi seca em estufa com ar forçado a $65{ }^{\circ} \mathrm{C}$ até atingir massa constante para a determinação da produção de matéria seca (MS) em balança de precisão. Em seguida, este material vegetal foi moído para posterior determinação dos teores totais de $\mathrm{P}$ e $\mathrm{Cu}$ nos tecidos vegetais. A outra porção da MF foi reservada para a determinação dos parâmetros fisiológicos, os quais serão descritos posteriormente.

Para avaliação da colonização micorrízica, aproximadamente 2,0 g de raízes foram submetidas à clarificação e coloração com azul de tripan (Koske e Gemma, 1989) e a percentagem da colonização micorrízica foi determinada pelo método das intersecções em placas reticuladas (Giovannetti e Mosse, 1980).

\section{Modelo matemático para estimativa de área foliar}

Para desenvolver o modelo matemático da estimativa de área foliar, foram obtidas aleatoriamente 90 folhas completas e sadias de diferentes tamanhos de plantas não utilizados no experimento (Borghezan et al., 2010).

Nas folhas selecionadas, o comprimento da nervura central foi mensurado com o uso de um paquímetro e a área foliar foi determinada através de um analisador portátil (ADC - AM 300). A relação entre a área foliar avaliada e o comprimento da nervura central resultou no modelo matemático (Figura 1), cuja equação foi utilizada para estimar a área foliar das videiras componentes do experimento através da mensuração do comprimento das nervuras centrais de todas as folhas das plantas.

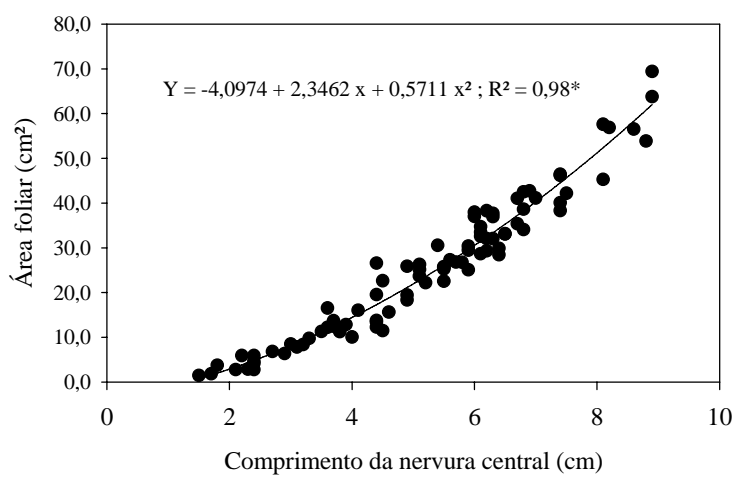

Figura 1. Modelo matemático para estimar a área foliar através do comprimento da nervura central em porta-enxerto 'P1103' (Vitis berlandieri $x$ Vitis rupestris) cultivado em solo com alto teor de $\mathrm{Cu}$.

Mathematical model to estimate leaf area across the length of the center rib in rootstock 'P1103' (Vitis berlandieri $x$ Vitis rupestris) grown in soil with high copper content.

Análises dos teores totais de P e Cu nas folhas, caule e raízes

Para a determinação dos teores totais de $\mathrm{P}$ foi realizada a digestão sulfúrica do material seguida de quantificação em espectrofotômetro (Tedesco et al., 1995), e para a determinação dos teores totais de $\mathrm{Cu}$ foi realizada a digestão a $500-550{ }^{\circ} \mathrm{C}$ por três horas, com posterior diluição em HNO3 $\left(1 \mathrm{~mol} \mathrm{~L}^{-1}\right)$ seguida de quantificação em espetrômetro de absorção atômica (Embrapa, 1997). O acúmulo dos nutrientes na planta foi calculado pela multiplicação do teor de cada nutriente pela sua respectiva MS da parte aérea. Posteriormente, foi calculada a porcentagem relativa do $\mathrm{Cu}$ acumulado em cada órgão da planta, adotando como referência (valor igual a 100\%) o total do nutriente acumulado na planta inteira.

\section{Avaliação dos parâmetros fisiológicos}

\section{Trocas gasosas}

As medições de trocas gasosas foram realizadas no $75^{\circ}$ dia de cultivo com um analisador portátil de $\mathrm{CO}_{2}$ por infravermelho (IRGA), LI-6200 (LICOR, USA), sendo a área da câmara de $6 \mathrm{~cm}^{2}$, volume de $250 \mathrm{~mL}$ 
e concentração de $\mathrm{CO}_{2}$ do ar de 380 ppm. Foram avaliadas as taxas de assimilação de $\mathrm{CO}_{2}$, condutância estomática e de transpiração. As avaliações foram realizadas na décima semana de cultivo, entre 9 e 11 horas da manhã, com luminosidade controlada de $1000 \mu \mathrm{mol}$ fóton $\mathrm{m}^{-2} \mathrm{~s}^{-1}$. Para essa avaliação, foi utilizada como padrão a quinta folha de cada planta, contada da base ao ápice.

\section{Análises de pigmentos fotossintéticos e acúcares}

A determinação do conteúdo de clorofilas e carotenoides nas folhas foi realizada pela extração com dimetilsulfóxido (DMSO) em banho-maria a 65 ${ }^{\circ} \mathrm{C}$ por duas horas, sem maceração e com determinação por meio de espectrofotometria (Hiscox e Israelstam, 1979). Os cálculos para a determinação da concentração das clorofilas a, b e total e de carotenoides foram realizados utilizando as fórmulas de Wellburn (1994).

A quantificação dos carboidratos solúveis totais foi realizada pelo método fenol-sulfúrico, utilizando $0,5 \mathrm{~g}$ de MF triturada em nitrogênio líquido até obtenção de um pó homogêneo e tendo como padrão a glucose (Dubois et al., 1956). Para a determinação do teor de amido total nas folhas, o precipitado resultante da extração dos carboidratos solúveis totais foi submetido à solubilização do amido com ácido perclórico (McCready et al., 1950) e quantificado pelo método fenol-sulfúrico, utilizando glucose como padrão (Dubois et al., 1956).

\section{Análises estatísticas}

Os dados de colonização micorrízica e a porcentagem relativa do $\mathrm{Cu}$ acumulado foram transformados em arco seno da raiz quadrada da porcentagem para a homogeneização da variância. Em seguida, todos os dados obtidos foram submetidos ao teste de Cochran para verificar a homocedasticidade. Posteriormente, realizou-se a análise de variância e, quando houve significância estatística, aplicou-se o teste de separação de médias Tukey $(\mathrm{p}<0,05)$. Além disso, foi realizada análise de correlação linear de Pearson entre as variáveis dependentes, cujas significâncias foram avaliadas pelo teste $t(p<0,05)$. Os valores de $F$ e coeficientes de variação das variáveis analisadas podem ser verificados no Quadro I. Para a realização das análises estatísticas foi utilizado o software livre 'Assistat versão 7.7 Beta'.

\section{RESULTADOS E DISCUSSÃO}

A maior colonização das raízes foi observada nas videiras inoculadas com $R$. clarus (40\% das raízes colonizadas), seguido pelas videiras inoculadas com D. heterogama e A. morrowiae (ambas com $25 \%$ das raízes colonizadas). As videiras sem inoculação não apresentaram colonização com FMA (Figura 2d).

\section{QUADRO I}

Valores de F e coeficientes de variação das variáveis analisadas em plantas de videira 'P1103' (Vitis berlandieri x Vitis rupestris) cultivadas em solo com alto teor de Cobre e inoculação com FMA

Values of $\mathrm{F}$ and coefficients of variation of the variables analyzed in vine plants 'P1103' (Vitis berlandieri $x$ Vitis rupestris) grown in soil with high copper content and inoculation with AMF

\begin{tabular}{|c|c|c|}
\hline Variável & $\mathbf{F}$ & $\mathrm{CV}(\%)$ \\
\hline Colonização micorrízica (\%) & $42,95 * *$ & 29,62 \\
\hline MS Folhas (g) & $7,04 * *$ & 13,96 \\
\hline MS Caule (g) & $12,46^{* *}$ & 18,93 \\
\hline MS Raizes (g) & $1,23^{\mathrm{ns}}$ & 26,27 \\
\hline Altura de planta $(\mathrm{cm})$ & $6,21^{* *}$ & 11,20 \\
\hline Número de folhas & $0,14^{\mathrm{ns}}$ & 12,96 \\
\hline Diâmetro do colmo (mm) & $1,18^{\text {ns }}$ & 13,67 \\
\hline Área foliar $\left(\mathrm{cm}^{2}\right)$ & $0,29^{\mathrm{ns}}$ & 14,40 \\
\hline Teor de $\mathrm{P}$ nas raízes ( $\mathrm{g} \mathrm{kg}^{-1} \mathrm{MS}$ ) & $7,05^{* *}$ & 24,82 \\
\hline Teor de $\mathrm{P}$ no caule ( $\mathrm{g} \mathrm{kg}^{-1} \mathrm{MS}$ ) & $9,24 * *$ & 20,95 \\
\hline Teor de P nas folhas ( $\mathrm{g} \mathrm{kg}^{-1} \mathrm{MS}$ ) & $8,40 * *$ & 32,49 \\
\hline Acúmulo de $\mathrm{P}$ nas raízes (mg planta ${ }^{-1}$ ) & $7,39 * *$ & 31,97 \\
\hline Acúmulo de $\mathrm{P}$ no caule (mg planta ${ }^{-1}$ ) & $24,06 * *$ & 22,63 \\
\hline Acúmulo de $\mathrm{P}$ nas folhas (mg planta ${ }^{-1}$ ) & $3,94 *$ & 31,11 \\
\hline Teor de Cu nas raízes (mg kg ${ }^{-1} \mathrm{MS}$ ) & $23,72 * *$ & 22,02 \\
\hline Teor de Cu no caule (mg kg-1 MS) & $0,93^{\mathrm{ns}}$ & 21,72 \\
\hline Teor de Cu nas folhas (mg kg-1 MS) & $3,34 *$ & 25,76 \\
\hline Acúmulo de Cu nas raízes ( $\mu$ g planta ${ }^{-1}$ ) & $9,50 * *$ & 30,44 \\
\hline Acúmulo de Cu no caule ( $\mu$ g planta ${ }^{-1}$ ) & $0,64^{\mathrm{ns}}$ & 33,10 \\
\hline Acúmulo de Cu nas folhas ( $\mu$ g planta ${ }^{-1}$ ) & $2,81^{\mathrm{ns}}$ & 30,86 \\
\hline Percentual de acúmulo de Cu na raiz (\%) & $1,30^{\mathrm{ns}}$ & 13,50 \\
\hline Percentual de acúmulo de Cu no caule (\%) & $2,40^{\mathrm{ns}}$ & 15,46 \\
\hline Percentual de acúmulo de Cu na folha (\%) & $2,62^{\mathrm{ns}}$ & 8,67 \\
\hline Assimilação de $\mathrm{Co}_{2}\left(\mu \mathrm{mol} \mathrm{m} \mathrm{m}^{2} \mathrm{~s}^{-1}\right)$ & $7,34 * *$ & 20,91 \\
\hline Condutância estomática $\left(\mu \mathrm{mol} \mathrm{m} \mathrm{m}^{2} \mathrm{~s}^{-1}\right)$ & $14,45^{* *}$ & 22,39 \\
\hline Transpiração (mmol m² $\left.\mathrm{s}^{-1}\right)$ & $22,29 * *$ & 18,88 \\
\hline Carboidratos solúveis totais ( $\mathrm{mg} \mathrm{g}^{-1} \mathrm{MF}$ ) & $4,30 *$ & 14,54 \\
\hline Amido total (mg g $\left.{ }^{-1} \mathrm{MF}\right)$ & $0,46^{\text {ns }}$ & 15,90 \\
\hline Clorofila $a\left(\mathrm{mg} \mathrm{g}^{-1} \mathrm{MF}\right)$ & $0,14^{\mathrm{ns}}$ & 10,05 \\
\hline Clorofila $b\left(\mathrm{mg} \mathrm{g}^{-1} \mathrm{MF}\right)$ & $0,67^{\mathrm{ns}}$ & 12,63 \\
\hline Clorofila total ( $\mathrm{mg} \mathrm{g}^{-1} \mathrm{MF}$ ) & $0,12^{\mathrm{ns}}$ & 9,75 \\
\hline Carotenoides ( $\mathrm{mg} \mathrm{g}^{-1} \mathrm{MF}$ ) & $1,39^{\text {ns }}$ & 12,03 \\
\hline
\end{tabular}

A associação micorrízica pode ser estimulada pela carência de $\mathrm{P}$ disponível à planta (Hippler e Moreira, 2013). No entanto, o teor de $\mathrm{P}$ disponível no solo do presente experimento foi de $34,8 \mathrm{mg} \mathrm{kg}^{-1}$, o que é considerado alto para solos com menos de $20 \%$ de argila (CQFS-RS/SC, 2004). Num estudo de colonização micorrízica em raízes de videiras jovens 'P1103' em substrato sem contaminação por metais e baixo teor de P, Zemke et al. (2003) obtiveram 
porcentagens de colonização de $25 \%$ nas raízes, o que está de acordo com os resultados obtidos no presente trabalho para a colonização por $D$. heterogama e $A$. morrowiae, mas inferior aos obtidos para a colonização por $R$. clarus.

Em estudo com videira, Schreiner (2007) observou 67 e $43 \%$ de colonização micorrízica em raízes de videiras cultivadas em solo com baixo e alto teor de $\mathrm{P}$, respectivamente. Por outro lado, o autor também verificou que o elevado teor de $\mathrm{P}$ não prejudicou a colonização das raízes por FMA. Portanto, é possível que os resultados de colonização micorrízica nas raízes de videiras jovens no presente experimento fossem mais elevados, caso o teor de $\mathrm{P}$ fosse baixo.
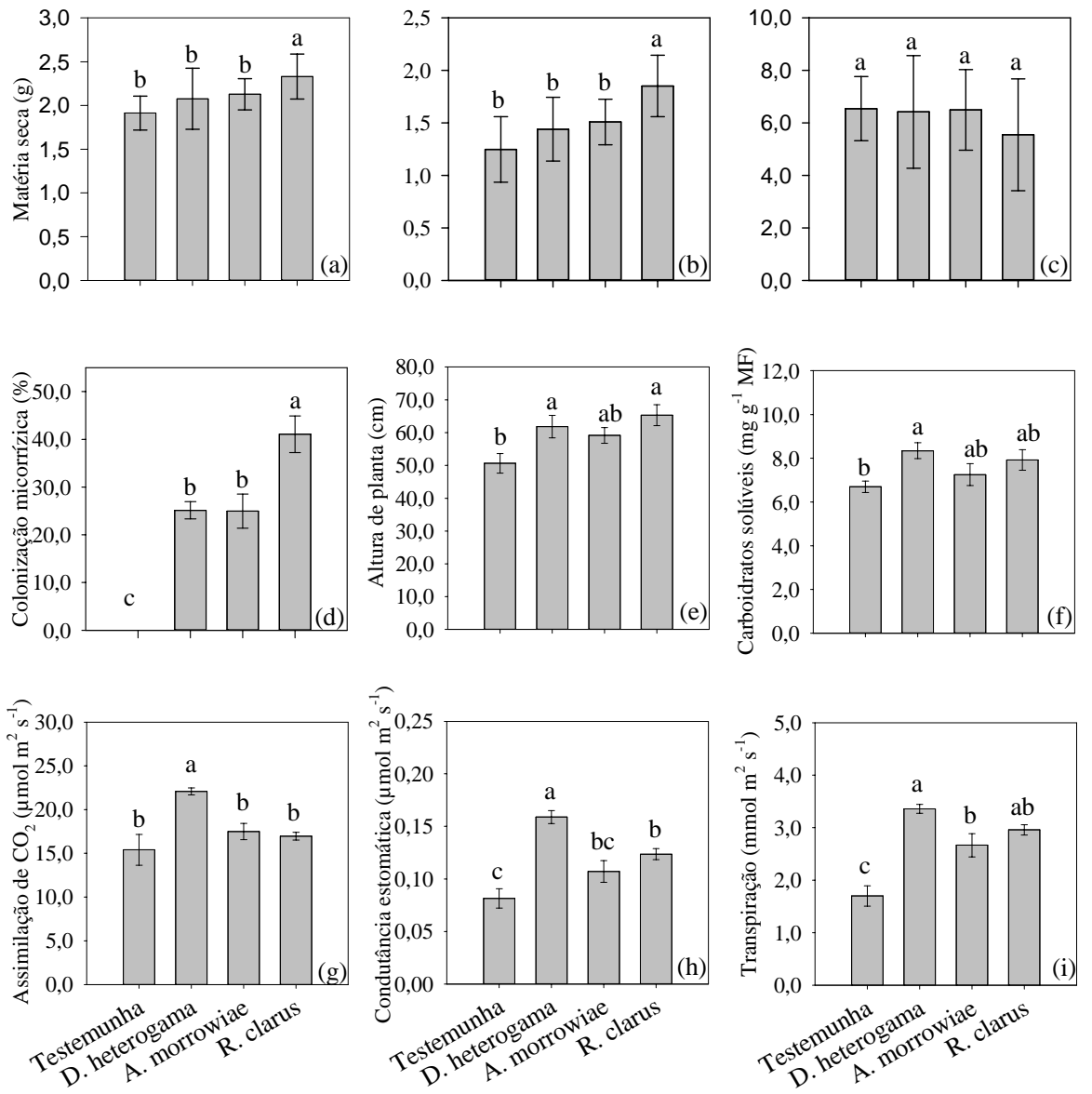

Figura 2. Matéria seca de folhas (a), caules (b) e raízes (c); colonização micorrízica (d); altura de planta (e); teor de carboidratos solúveis totais (f); taxa de assimilação de $\mathrm{CO}_{2}$ (g); taxa de condutância estomática (h); taxa de transpiração (i), em porta-enxerto de videiras jovens 'P1103’ (Vitis berlandieri $x$ Vitis rupestris), cultivadas em solo com alto teor de Cu e inoculação de FMA. As barras representam o erro padrão.

Leaf dry matter (a), stem (b) and roots (c); mycorrhizal colonization (d); plant height (e); total soluble carbohydrate content (f); $\mathrm{CO}_{2}$ assimilation rate (g); Stomatal conductance rate (h); transpiration rate (i) in the rootstock of young vines 'P1103' (Vitis berlandieri $x$ Vitis rupestris), grown in soil with high content of $\mathrm{Cu}$ and $\mathrm{AMF}$ inoculation. The bars represent the standard error.

A inoculação das plantas de videiras jovens contribuiu para aumentar o crescimento em altura, verificada no final do experimento, cujos resultados foram superiores quando inoculadas com $R$. clarus e 
D. heterogama, seguidos de A. morrowiae, e a menor altura foi observada nas videiras sem inoculação com FMA (Figura 2e). Esses resultados são reforçados pela correlação positiva significativa entre a altura das plantas e a porcentagem de colonização micorrízica ( $\mathrm{r}$ $\left.=0,98^{* *}\right)$.

A maior produção de MS das folhas e caule das videiras inoculadas com $R$. clarus, assim como a maior altura de planta quando inoculadas com $R$. clarus e $D$. heterogama, pode ser consequência da capacidade simbiótica das espécies de FMA em amenizar o estresse causado pelo alto teor de $\mathrm{Cu}$ no solo. Este processo pode ocorrer pela compartimentalização do $\mathrm{Cu}$ no vacúolo e também pela liberação de glomalina pelas raízes, que pode complexar o $\mathrm{Cu}$, reduzindo significativamente os seus danos no metabolismo da planta (Cornejo et al., 2013; Saba et al., 2013). Além disso, esses fungos provavelmente aumentaram a absorção de água e outros nutrientes, especialmente o $\mathrm{P}$, contribuindo para uma melhor nutrição da planta (Gupta et al., 2014). A produção de MS observada corrobora com os resultados obtidos por Ambrosini et al. (2015), em estudo com videiras jovens inoculadas com seis espécies de FMA, onde as videiras inoculadas $\operatorname{com} R$. clarus apresentaram maior produção de MS.

A inoculação das videiras jovens com as três espécies de FMA não afetaram o número de folhas, diâmetro do colmo e área foliar (Quadro II). Possivelmente, por o $\mathrm{Cu}$ ter ficado em maior quantidade nas raízes (Figura 3), a quantidade transportada para o caule e folhas das videiras não foi elevada a ponto de causar danos graves no metabolismo e inibir o desenvolvimento dos mesmos (Kabata-Pendias, 2011).

\section{QUADRO II}

Número de folhas, diâmetro do colmo, área foliar, amido total, clorofila $a, b$ e total, carotenoides nas plantas de porta-enxerto de videira 'P1103' (Vitis berlandieri $x$ Vitis rupestris) cultivadas em solo com alto teor de Cu e inoculação de FMA

Number of leaves, stem diameter, leaf area, total starch, chlorophyll a, b and total carotenoids in plants rootstock grapevine 'P1103' (Vitis berlandieri $x$ Vitis rupestris) grown in soil with high content of Cu and AMF inoculation

\begin{tabular}{|c|c|c|c|c|}
\hline \multirow[b]{2}{*}{ Variável } & \multicolumn{4}{|c|}{ FMA } \\
\hline & Sem inóculo & D. heterogama & A. morrowiae & R. clarus \\
\hline Número de folhas & $14^{\mathrm{ns}}$ & 15 & 14 & 14 \\
\hline Diâmetro do colmo (mm) & $0,32^{\mathrm{ns}}$ & 0,34 & 0,32 & 0,36 \\
\hline Área foliar $\left(\mathrm{cm}^{2}\right)$ & $379,77^{\mathrm{ns}}$ & 403,84 & 383,79 & 380,72 \\
\hline Amido total (mg g ${ }^{-1} \mathrm{MF}$ ) & $1,12^{\mathrm{ns}}$ & 1,06 & 1,05 & 1,11 \\
\hline Clorofila $a\left(\mathrm{mg} \mathrm{g}^{-1} \mathrm{MF}\right)$ & $2,23^{\mathrm{ns}}$ & 2,18 & 2,20 & 2,16 \\
\hline Clorofila $b$ (mg g $\left.{ }^{-1} \mathrm{MF}\right)$ & $0,81^{\mathrm{ns}}$ & 0,85 & 0,87 & 0,83 \\
\hline Clorofila total (mg g $\left.{ }^{-1} \mathrm{MF}\right)$ & $3,04^{\mathrm{ns}}$ & 3,04 & 3,08 & 3,00 \\
\hline Carotenoides (mg g ${ }^{-1} \mathrm{MF}$ ) & $0,43^{\mathrm{ns}}$ & 0,39 & 0,40 & 0,39 \\
\hline
\end{tabular}

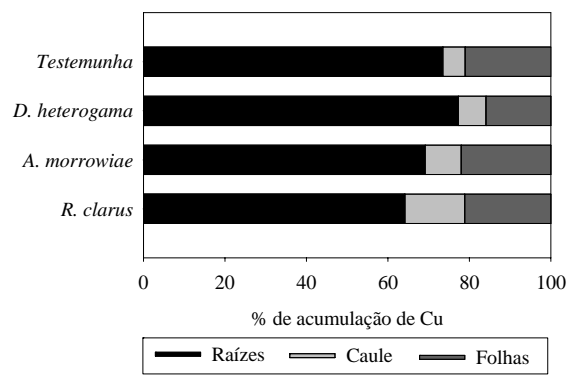

Figura 3. Porcentagem de acumulação de Cu nas raízes, caule e folhas em porta-enxerto de videiras jovens 'P1103' (Vitis berlandieri $x$ Vitis rupestris), cultivadas em solo com alto teor de $\mathrm{Cu}$ e inoculação de FMA.

Percentage of $\mathrm{Cu}$ accumulation in roots, stems and leaves of rootstock of young vines 'P1103' (Vitis berlandieri $x$ Vitis rupestris), grown in soil with high content of Cu and AMF inoculation.

O maior teor de $\mathrm{P}$ total nas raízes, caule e folhas foi observado nas videiras inoculadas por $R$. clarus (Figura 4a, 4b e 4c), que aumentou o teor de P em 56, 84 e 43\%, respectivamente, nesses órgãos, em relação às videiras não micorrizadas. $\mathrm{O}$ acúmulo de $\mathrm{P}$ nas raízes, caule e folhas foi 90, 115 e 50\% maiores, respectivamente, nas videiras inoculadas com $R$. clarus (Figura 4d, 4e e 4f). O teor e acúmulo de $\mathrm{P}$ nas raízes, caule e folhas não diferiram estatisticamente entre as videiras inoculadas com $D$. heterogama e $A$. morrowiae, daquelas sem inoculação. $\mathrm{O}$ maior incremento de $\mathrm{P}$ nas raízes, caules e folhas, e a maior colonização micorrízica nas videiras inoculadas com $R$. clarus corrobora com os resultados obtidos por 
Ambrosini et al. (2015) em estudo com videiras jovens 'P1103'.
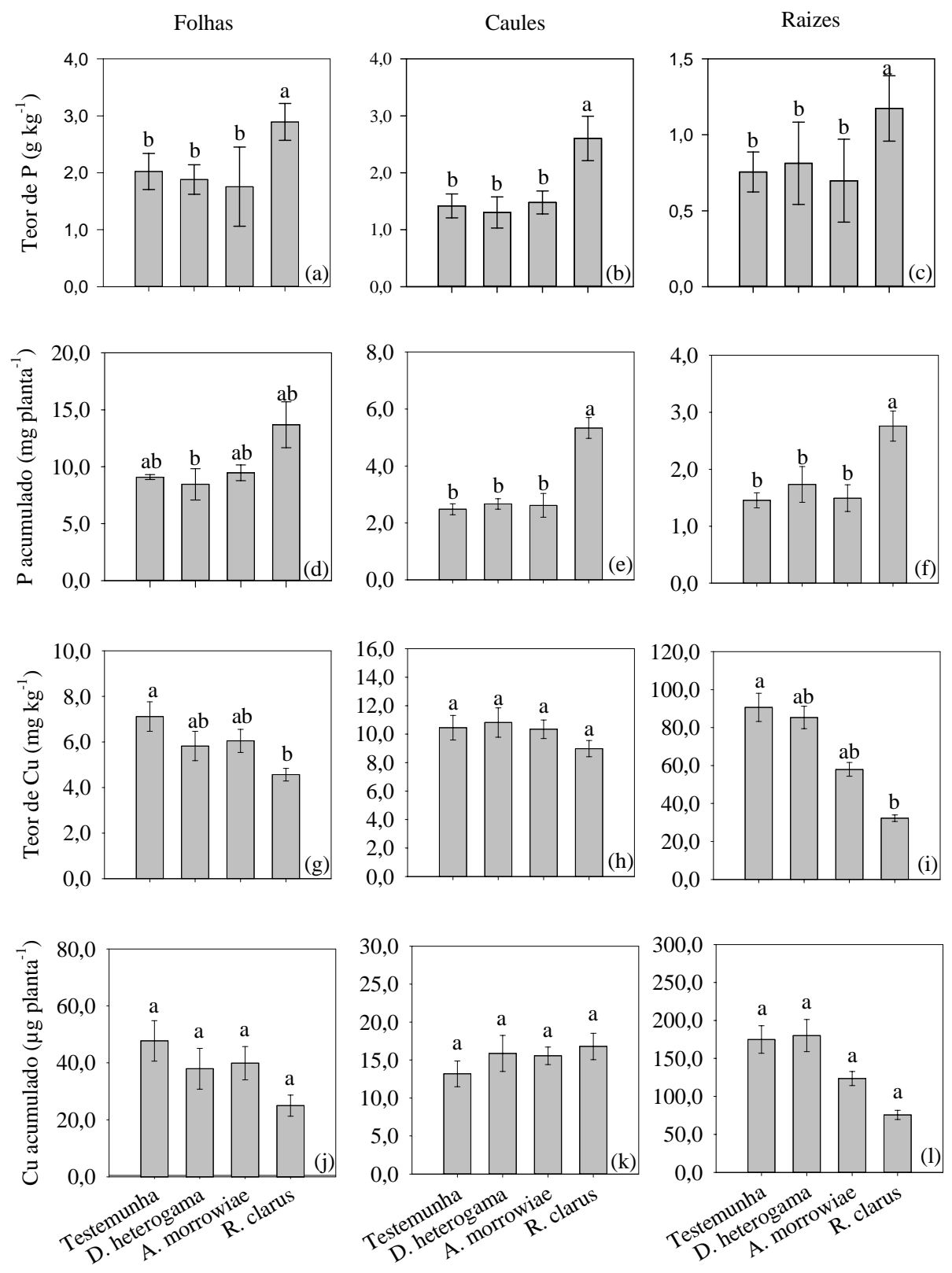

Figura 4. Teor de P em folhas (a), em caules (b) e em raízes (c); P acumulado em folhas (d), em caules (e) e em raízes (f); Teor de Cu em folhas (g), em caules (h) e raízes (i); Cu acumulado em folhas (j), em caules (k) e em raízes (l); em porta-enxerto de videiras jovens 'P1103' (Vitis berlandieri $x$ Vitis rupestris), cultivadas em solo com alto teor de Cu e inoculação de FMA. As barras representam o erro padrão.

Leaves content of $P(a)$ in stems $(b)$ and roots (c); P accumulated in leaves $(d)$ in stems $(e)$ and roots $(f)$; Cu content in leaves $(g)$ in stems $(h)$ and roots (i); Cu accumulated in leaves $(j)$, in stems ( $k$ ) and roots (l); on rootstock of young vines 'P1103' (Vitis berlandieri $x$ Vitis rupestris), grown in soil with high content of $\mathrm{Cu}$ and $\mathrm{AMF}$ inoculation. The bars represent the standard error.

O P quando foi absorvido em maior quantidade pelas raízes, também foi encontrado em maior concentração no caule e nas folhas, evidenciando o transporte do nutriente até a parte aérea das plantas. É importante a 
contribuição dos FMA na nutrição das plantas, pois o $\mathrm{P}$, na forma de fosfato, é componente de compostos como os açúcares fosfatados, incluindo glicose e frutose, fosfolipídios de membranas, adenosina trifosfato (ATP) e ácidos nucléicos (Marschner, 2012).

$\mathrm{O}$ aumento do teor de $\mathrm{P}$ total e de $\mathrm{P}$ acumulado em todos os órgãos das videiras jovens inoculadas com $R$. clarus pode estar associado à maior colonização micorrízica nas raízes das videiras por essa espécie (Figura 2d). A associação micorrízica promove a melhoria do estado nutricional de $\mathrm{P}$ das plantas, o que favorece o crescimento de plantas expostas a níveis tóxicos de metal pesado (Soares e Siqueira, 2008; Andrade et al., 2010; Pigna et al., 2014).

As videiras inoculadas com o $R$. clarus apresentaram o menor teor de $\mathrm{Cu}$ nas folhas e raízes, que correspondeu a uma diminuição de $37 \%$ e $61 \%$, respectivamente, em comparação com as videiras não micorrizadas (Figuras 4g, 4i). As videiras inoculadas com D. heterogama e A. morrowiae também apresentaram teores de $\mathrm{Cu}$ nas folhas (18 e 15\%, respectivamente) e nas raízes (6 e 36\%, respectivamente), em comparação com as videiras não micorrizadas. No entanto, essa redução não foi suficiente para diferir estatisticamente das videiras sem inoculação e daquelas inoculadas como $R$. clarus.

$\mathrm{O} \mathrm{Cu}$ acumulado nas folhas e no caule (Figura 4j, 4k) não sofreu diminuição pelos FMA, mas o $\mathrm{Cu}$ acumulado nas raízes das videiras inoculadas com $R$. clarus diminuiu 57\%, em relação às videiras sem inoculação (Figura 3l).

A redução do teor de $\mathrm{Cu}$ nas raízes, no caule e nas folhas e do acúmulo de $\mathrm{Cu}$ nas raízes das videiras inoculadas com $R$. clarus indica a redução na absorção do metal pelas videiras associadas a essa espécie de FMA. Isso pode ter acontecido por causa de estratégias utilizadas pelos FMA para sobreviver no solo com alto teor de $\mathrm{Cu}$ e que, consequentemente, proporcionam a redução na absorção do metal pelas plantas, como: a produção e liberação de glomalina no solo, que pode diminuir a disponibilidade de $\mathrm{Cu}$ no solo por causa da sua alta reatividade (Folli-Pereira et al., 2012) e a retenção do metal no micélio fúngico ou em alguns esporos, que pode reduzir a sua absorção (Cornejo et al., 2013).

A distribuição de $\mathrm{Cu}$ no interior da planta não foi influenciada pelos FMA (Figura 3). No entanto, era esperado que a inoculação com FMA proporcionasse a percentagem relativa do $\mathrm{Cu}$ nas folhas, aumentando nas raízes. Isso porque, o incremento de $\mathrm{P}$ no interior da planta reduz o transporte de metais das raízes para a parte aérea, amenizando a toxicidade de metais, como relatado por Soares e Siqueira (2008) em plantas de braquiária (Brachiaria decumbens Stapf.), submetidas a elevados teores de $\mathrm{Cu}$, zinco ( $\mathrm{Zn}$ ) e cádmio (Cd), o que também concordam com resultados de Pigna et al. (2014), em plantas de escarola (Cichorium endivia L.) cultivadas em solo com alto teor de Arsênio (As).

Como não houve diferença na distribuição de $\mathrm{Cu}$ nos órgãos das videiras jovens, calculou-se, usando a média de todos os tratamentos, a relação entre o teor e o acúmulo de $\mathrm{Cu}$ nas raízes e nas folhas. Essa relação foi de 11,3 para o teor de Cu e de 3,7 para o acúmulo de $\mathrm{Cu}$. Estes valores indicam que as videiras jovens reduziram a passagem do $\mathrm{Cu}$ das raízes para as folhas. Isso ocorreu porque a planta possui estratégias como a compartimentalização do metal nos vacúolos, a quelação na interface da membrana plasmática e a complexação intracelular por substâncias orgânicas, que são eficientes para diminuir o transporte para as folhas, onde causariam danos mais graves no metabolismo (Yruela, 2009; Saba et al., 2013). Como consequência, o teor do metal nas folhas esteve dentro da faixa considerada normal para a maioria das plantas, que é entre 5 e $30 \mathrm{mg} \mathrm{kg}^{-1}$ segundo KabataPendias (2011), mesmo nas plantas sem inoculação micorrízica (Figura 4g).

A taxa de assimilação de $\mathrm{CO}_{2}$ (Figura $2 \mathrm{~g}$ ) foi maior nas videiras jovens inoculadas com $D$. heterogama que também apresentou o maior resultado para a condutância estomática (Figura 2h) e a transpiração (Figura 2i). Para a taxa de assimilação de $\mathrm{CO}_{2}$ observou-se que as videiras inoculadas com $A$. morrowiae e $R$. clarus não diferiram das videiras sem inoculação. Já para a condutância estomática e a transpiração o menor resultado foi verificado nas videiras não micorrizadas.

A maior taxa de assimilação de $\mathrm{CO}_{2}$ (Figura 2g), condutância estomática (Figura 2h) e a maior transpiração (Figura 2i) verificadas nas videiras jovens inoculadas com $D$. heterogama pode ser resultado da maior absorção de água e nutrientes, proporcionada por essa espécie fúngica. Isso se fundamenta na simbiose obrigatória que exige da planta a transferência de compostos de carbono às hifas, sendo que o custo total em hidratos de carbono pode chegar a $20 \%$ da produção da fotossíntese (Boldt et al., 2011; Adolfsson et al., 2015). Assim, a planta passa a assimilar $\mathrm{CO}_{2}$ de forma mais eficiente para compensar a demanda de hidratos de carbono como estratégia de garantir a continuidade da simbiose e beneficiar da melhor nutrição proporcionada pelo FMA (Adolfsson et al., 2015). 
A inoculação das raízes das plantas com FMA também pode melhorar a eficiência dos fotossistemas. Em estudo com tomateiros, Boldt et al. (2011), verificaram que a fluorescência da clorofila, e o rendimento quântico máximo do fotossistema II (PSII) das plantas foi significativamente superior com a inoculação por FMA. Isso aumentou a capacidade das plantas em usar a energia de forma mais eficiente com maiores taxas de transporte de elétrons (Boldt et al., 2011).

O teor de carboidratos solúveis totais nas folhas das videiras jovens, foi maior nas plantas de videira inoculadas com D. heterogama (Figura 2f). Este facto está provavelmente relacionado com a maior assimilação de $\mathrm{CO} 2$ nessas plantas (Figura 2g), que resulta em aumento da atividade do ciclo de Calvin, originando maiores quantidades de hidratos de carbono na folha, principalmente sacarose e amido (Boldt et al., 2011). As videiras inoculadas com $A$. morrowiae e $R$. clarus apresentaram concentrações menores de carboidratos solúveis totais mas não diferenciaram das plantas inoculadas com $D$. heterogama. As videiras sem inoculação apresentaram a menor concentração de carboidratos solúveis totais.

O teor de amido total nas folhas das videiras jovens não foi influenciado pela inoculação dos isolados de FMA (Quadro II). Isso pode ter acontecido em função do tempo de cultivo ser insuficiente para a videiras acumularem amido, visto que as videiras jovens estavam em pleno crescimento e, provavelmente, estavam utilizando a energia para a formação de folhas e incremento em biomassa para o estabelecimento da planta.

Os teores de clorofila a, b, total e de carotenoides não foram influenciados pelos tratamentos (Quadro II). Quando em altos teores para a planta, o $\mathrm{Cu}$ pode diminuir os teores dos pigmentos fotossintetizantes nas folhas das plantas por causar deficiência de ferro (Fe). Além disso, o excesso de $\mathrm{Cu}$ absorvido e transportado para a parte aérea pode causar a substituição do Mg pelo Cu na molécula de clorofila, inibindo a fotossíntese (Yruela, 2009). Pela ausência de resposta dos tratamentos, supõem-se que, mesmo

\section{REFERÊNCIAS BIBLIOGRÁFICAS}

Adolfsson L., Solymosi K., Andersson M.X., Keresztes A., 2015. Mycorrhiza symbiosis increases the surface for sunlight capture in Medicago truncatula for better photosynthetic production. Plos One, 10, 1-18.

Alaoui-Sossé B., Genet P., Vinit-Dunand F., Toussaint M.L., Epron D., Badot P.M., 2004. Effect of copper on growth in cucumber plants (Cucumis sativus) and its relationships with carbohydrate nas videiras sem inoculação micorrízica, o $\mathrm{Cu}$ absorvido e transportado até as folhas não atingiu níveis tóxicos capazes de modificar a síntese de moléculas de clorofila.

A clorofila a foi mais abundante que a clorofila b em todas as videiras, mantendo uma relação clorofilas a/b média de 2,6, estando de acordo com os valores e proporções encontradas por Amarante et al. (2009), em videiras jovens de 'Cabernet Sauvignon' cultivadas em solo contendo excesso de metais pesados e sem inoculação por FMA.

É importante observar que os FMAs não alteraram a distribuição do Cu na planta e também não reduziram o acúmulo do metal nas folhas. Porém, a espécie $R$. clarus proporcionou vários outros benefícios às videiras jovens, como o incremento de $\mathrm{P}$ no interior da planta, que se refletiu em promoção do crescimento e da biomassa das videiras. O maior crescimento das videiras, por sua vez, se refletiu na redução do teor de $\mathrm{Cu}$ nas folhas, como um efeito de diluição dentro do órgão, o que pode ser comprovado pela correlação significativa entre o teor de $\mathrm{Cu}$ na folha e colonização micorrízica ( $\left.\mathrm{r}=-0,96^{* *}\right)$, altura da planta $\left(\mathrm{r}=-0,95^{* *}\right)$, MS de folha $\left(\mathrm{r}=-0,97^{* *}\right)$ e de caule $(r=-0,99 * *)$.

\section{CONCLUSÕES}

A inoculação das videiras jovens com FMA contribui para o estabelecimento da planta em solo com alto teor de $\mathrm{Cu}$. Os benefícios proporcionados às videiras pela associação simbiótica variaram entre as espécies de FMA. Destaca-se $R$. clarus, o qual promoveu maior produção de biomassa de folha e caule, maior absorção de $\mathrm{P}$ com consequente redução no teor de $\mathrm{Cu}$ nos tecidos das videiras jovens cultivadas em solo contaminado. As videiras inoculadas com $D$. heterogama obtiveram as melhores taxas de assimilação de $\mathrm{CO}_{2}$, condutância estomática, transpiração e consequentemente, o maior teor de carboidratos solúveis totais. Os teores das clorofilas e de amido total não foram influenciados pela inoculação das plantas com FMA.

accumulation and changes in ion contents. Plant Science, 166 1213-1218.

Amarante C.V.T., Zanardi O.Z., Miqueloto A., Steffens C.A., Erhart J., Almeida J.A., 2009. Quantificação da área e do teor de clorofilas em folhas de plantas jovens de videira 'Cabernet Sauvignon' mediante métodos não destrutivos. Rev. Brasileira de Fruticultura, 31, 680-686.

Ambrosini V.G., Voges J.G., Canton L., Couto R.R., Ferreira P.A.A., Comin J.J., Melo G.W.B., Brunetto G., Soares C.R.F.S., 2015. Effect of arbuscular mycorrhizal fungi on young vines in 
copper-contaminated soil. Brazilian Jour. Microbiology, 46, 10451052

Andrade S.A.L., Silveira A.P.D., Mazzafera P., 2010. Arbuscular mycorrhiza alters metal uptake and the physiological response of Coffea arabica seedlings to increasing $\mathrm{Zn}$ and $\mathrm{Cu}$ concentrations in soil. Sci. of the Total Environment, 408, 5381-5391.

Boldt K., Pörs Y., Haupt B., Bitterlich M., Kühn C., Grimm B., Franken P., 2011. Photochemical processes, carbon assimilation and RNA accumulation of sucrose transporter genes in tomato arbuscular mycorrhiza. Jour. of Plant Physiology, 168, 1256-1263.

Borghezan M., Gavioli O., Pit F.A., Silva A.L., 2010. Modelos matemáticos para a estimativa da área foliar de variedades de videira à campo (Vitis vinifera L.). Ciência Téc. Vitiv., 25, 1-7.

Cambrollé, J., García, J.L., Figueroa, M. E., Cantos, M., 2015. Evaluating wild grapevine tolerance to copper toxicity. Chemosphere, 120C 171-178.

Cornejo P., Pérez-Tienda J., Meier S., Valderas A., Borie F., Azcón-Aguilar C., Ferrol N., 2013. Copper compartmentalization in spores as a survival strategy of arbuscular mycorrhizal fungi in Cu-polluted environments. Soil Biol. and Biochemistry, 57, 925928.

CQFS-RS/SC., 2004. Manual de adubação e calagem para os Estados do Rio Grande do Sul e de Santa Catarina. 10 ed. EMBRAPA, Porto Alegre.

Dubois M., Gilles K.A., Hamilton J.K., Rebers P.A., Smith F. 1956. Colorimetric method for determination of sugars and related substances. Analytical Chemistry, 28, 350-356.

EMBRAPA, 1997. Manual de métodos de análise de solo. Rio de Janeiro: Embrapa Solos, p. 212.

EMBRAPA, 2013. Sistema brasileiro de classificação de solos. 3 Ed. Brasília, 2013.

Folli-Pereira M.S., Meira-Haddad L.S., Bazzolli D.M.S., Kasuya M.C.M., 2012. Micorriza arbuscular e a tolerância das plantas ao estresse. Revista Brasileira de Ciência do Solo, 36, 1663-1679.

Gerdemann J.W., Nicolson T.H., 1963. Spores of micorrhizal Endogene species extracted from soil by wet sieving and decanting. Trans. Brit. Mycol. Soc., 75, 235-244.

Giovannetti M., Mosse B., 1980. An evaluation of techniques for measuring vesicular arbuscular mycorrhizal infection in roots. New phytologist, 84, 489-500.

Girotto E., Ceretta C.A., Rossato L.V., Farias J.G., Tiecher T L., De Conti L., Schmatz R., Brunetto G., Schetinger M.R.C., Nicoloso F T., 2013. Triggered antioxidant defense mechanism in maize grown in soil with accumulation of $\mathrm{Cu}$ and $\mathrm{Zn}$ due to intensive application of pig slurry. Ecotox. and Environ. Safety, 93, 145-155.

Gupta D.K., Chatterjee S., Datta S., Veer V., Walther C., 2014. Role of phosphate fertilizers in heavy metal uptake and detoxification of toxic metals. Chemosphere, 108, 134-144.

Hippler F.W.R., Moreira M., 2013. Dependência micorrízica do amendoinzeiro sob doses de fósforo. Bragantia, 72, 184-191.

Hiscox J.D., Israelstam G.F., 1979. A method for the extraction of chlorophyll from leaf tissue without maceration. Can. Jour. of Botany, 57, 1332-1334.

Kabata-Pendias A., 2011. Trace elements in soils and plants. 505p. 4 Ed. Taylor e Francis Group, Boca Raton.
Koske R.E., Gemma J.N., 1989. A modified procedure for staining roots to detect VA mycorrhizas. Mycological Research, 92, 486488.

Kopittke P.M., Asher C., Blamey F.P.C., Menzies N. W., 2009. Toxic effects of $\mathrm{Cu}^{2+}$ on growth, nutrition, root morphology, and distribution of $\mathrm{Cu}$ in roots of Sabi grass. Sci. of the Total Environment, 407, 4616-4621.

Marschner P., 2012. Mineral Nutrition of Higher Plants. 651p, Elsevier, Oxford.

McCready R., Guggolz J., Silveira V., Owens H., 1950. Determination of starch and amylose in vegetables. Analytical Chemistry, 22, 1156-1158.

Meier S., Borie F., Curaqueo G., Bolan N., Cornejo P., 2012 Effects of arbuscular mycorrhizal inoculation on metallophyte and agricultural plants growing at increasing copper levels. Applied Soil Ecology, 61, 280-287.

Nachtigall G.R., Corrêa R., Reynaldo L., Alleoni,F., 2007. Formas de cobre em solos de vinhedos em função do $\mathrm{pH}$ e da adição de cama-de-frango. Rev. Bras. de Eng. Agricola e Ambiental, 7, 427434

Pigna M., Caporale A.G., Cartes P., Cozzolino V., Mora M., Sommella A., Violante A., 2014. Effects of arbuscular mycorrhizal inoculation and phosphorus fertilization on the growth of escarole (Cichorium endivia L.) in an arsenic polluted soil. Jour. of Soil Sci. and Plant Nutrition, 14, 199-209.

Saba H., Jyoti P., Neha S., 2013. Mycorrhizae and phytochelators as remedy in heavy metal contaminated land remediation. Inter. Research Jour. of Environ. Sciences, 2, 74-78.

Schreiner R. P., 2007. Effects of native and nonnative arbuscular mycorrhizal fungi on growth and nutrient uptake of "Pinot noir" (Vitis vinifera L.) in two soils with contrasting levels of phosphorus. Applied Soil Ecology, 36, 205-215.

Silva A., Doazan J., 1995. Une méthode d'irradiation aux rayons gamma appliquée à des porte-greffes de vigne in vitro. Jour. Inter. des Sciences de la Vigne et du Vin, 29, 1-9.

Soares C.R.F.S., Siqueira J.O., 2008. Mycorrhiza and phosphate protection of tropical grass species against heavy metal toxicity in multi-contaminated soil. Bio. and Fertility of Soils, 44, 833-841.

Sônego O., Garrido L., Júnio, A.G., 2005. Principais doenças fúngicas da videira no Sul do Brasil, 32p. Embrapa, Bento Gonçalves.

Tedesco M., Gianello C., Bissani C., 1995. Análises de solo, plantas e outros materiais. 174p. UFRGS, Porto Alegre.

Toselli M., Schiatti P., Ara D., Bertacchini A., Quartieri M., 2009. The accumulation of copper in soils of the Italian region EmiliaRomagna. Plant Soil Environ., 55, 74-79.

Wellburn A.R., 1994. The spectral determination of chlorophylls a and $b$, as well as total carotenoids, using various solvents with spectrophotometers of different resolution. Journal of Plant Physiology, 144, 307-313.

Yruela I., 2009. Copper in plants: acquisition, transport and interactions. Funct. Plant Biology, 36, 409-430.

Zemke J.M., Pereira F., Lovato, P.E., Da Silva A.L., 2003. Avaliação de substratos para inoculação micorrízica e aclimatização de dois porta-enxertos de videira micropropagados. Pesq. Agropecuária Brasileira, 38, 1309-1315. 